\title{
SYSTEMIC RISK IN TAIWAN STOCK MARKET
}

\author{
Her-Jiun Sheu ${ }^{1}$, Chien-Ling Cheng ${ }^{2}$ \\ ${ }^{1}$ Department of Banking and Finance, National Chi Nan University, No. 1, \\ University Road, Puli, Nantou County 54561, Taiwan \\ 2Institute of Business and Management, National Chiao Tung University, \\ No. 118 Chung-Hsiao W. Rd., Sec. 1, Chung-Cheng District, Taipei 100, Taiwan \\ E-mails: ${ }^{1}$ hjsheu@ncnu.edu.tw; ${ }^{2}$ marscheng@scsb.com.tw (corresponding author)
}

Received 02 May 2011; accepted 17 August 2011

\begin{abstract}
Recent financial crises resulted from systemic risk caused by idiosyncratic distress. In this research, taking Taiwan stock market as an example and collecting data from 2000 to 2010 which contained the 2001 dot-com bubble and the 2007-2009 financial crisis, we adopt the CoVaR model to empirically explore the impact of sector-specific idiosyncratic risk on the systemic risk of the system and attempt to investigate the links between financial crises, systemic risk and the idiosyncratic risk of a sector-specific anomaly. The result showed sector-specific marginal CoVaR, i.e., $\Delta \mathrm{CoVaR}$, perfectly explained Taiwan stock market disturbance during the 2001 dot-com bubble and 2007-2008 financial crisis. Thus, by identifying the larger $\Delta \mathrm{CoVaR}$ sectors, i.e. the systemic importance sectors, and by exploring the risk indicators, independent variables, of these systemic importance sectors, investors could practically employ the sector-specific $\Delta \mathrm{CoVaR}$ measure to deepen the systemic risk scrutiny from a macro into a micro prudential perspective.
\end{abstract}

Keywords: value at risk, Conditional VaR, systemic risk, idiosyncratic risk, financial crisis, spill over, systemic importance.

Reference to this paper should be made as follows: Sheu, H.-J.; Cheng, C.-L. 2012. Systemic risk in Taiwan stock market, Journal of Business Economics and Management 13(5): 895-914.

JEL Classification: F47, G01, G10, G15, G21.

\section{Introduction}

Many financial crises have resulted from systemic risk which is caused by idiosyncratic distress, leading to the crunch of the whole system. The interaction between financial distress and systemic risk due to the effect of idiosyncratic distress has been discussed recently (Fu 2009; Campbell et al. 2008; Ang et al. 2006). Amongst the idiosyncratic distress, sector-specific risk, which is caused by a group of interconnected institutions, has been given as the main reason for sudden increases in systemic risk, leading to the formalization of financial crises. In this research, taking Taiwan stock market as an example and collecting data from 2000 to 2010 which contained the 2001 dot-com bubble and the 2007-2009 financial crisis, we adopted the CoVaR model to empirically 
explore the impact of sector-specific idiosyncratic risk on the systemic risk of the whole financial system and attempt to investigate the links between financial crises, systemic risk, and the idiosyncratic risk of a sector-specific anomaly.

International stock market transmission across different markets has been comprehensively studied. Many recent studies have discussed the volatility spillover effect of stock market returns. These papers have shown some typical characteristics of the volatility spillover effect among different stock markets (Martens, Poon 2001; Goetzmann et al. 2001; Worthington, Higgs 2004; Michelfelder RA 2005; Scheicher 2001; Bekaert, Harvey 1997; Gokcan 2000; Sheu, Cheng 2011). In addition, within a stock market, during times of financial crisis, losses tend to spread from a single sector across other sectors, leading to increased system-wide risk and probable deterioration of the whole stock market system. This financial system instability or potential catastrophe, caused by idiosyncratic events and resulting in risk to the entire financial system, is defined as systemic risk. Many financial crises are initially caused by a "sector-specific" idiosyncratic distress of a country, then spill over across other sectors to increase systemic risk, consequently leading to worldwide crashes. These crises result from systemic risk, caused by idiosyncratic distress, which cannot be reduced through portfolio diversification. Several reasons might lead to systemic risk and there are two commonly used assessments for measuring systemic risk, i.e. the "too big to fail" and "too interconnected to fail" test. The "too big to fail" test considers an asset size relative to the marketplace, i.e. market share concentration and the "too interconnected to fail" measures the likelihood and extent of negative impact to the overall economic system from the failure of a group of correlated institutions.

Traditionally, value-at-risk (VaR) is widely used to access the risk of loss of specific financial assets and provides a measure to manage the market risk of assets. However, VaR focuses on these assets in isolation and does not consider external impacts. Using value-at-risk (VaR) to access assets, it seems negligible to capture the systemic risk and the true risk is often underestimated when other assets come under stress. For investors to control the risk for underlying assets, the appropriate risk measure could not only access the risk of a sector's economic activities itself, but also consider the impact to systemic risk from the idiosyncratic distress. Thus, to supplement the drawback of VaR for estimating market risk, it is necessary to employ more interdependent and comprehensive measures that could consider the interconnected nature of the financial system and gauge the increased systemic risk due to the distress of other financial assets. However, it was not until the financial crisis of 1998 that some researches begun to discuss systemic risk and develop approaches to measure it. Among these approaches, the "CoVaR" method, proposed by Adrian and Brummermeier (2008), is a more interdependent and comprehensive method and has been successfully employed to capture systemic risk.

Following this CoVaR method, the Taiwan stock market during periods of 2000-2010 was taken as an example to explore systemic risk caused by "sector-specific" distress for some reason. First, Taiwan rose to second in the world for global IT competitiveness through its strengths in R\&D and nurturing technology talent (Business Software Alli- 
ance 2008). Second, given the economic success of Taiwan in the last several decades, many global investors have taken an active interest and hold an index investment position in this stock market. Finally, the technology industry and financial industry rank as the top two important industries in Taiwan stock market. Thus, it is an appropriate objective to measure and backtest the systemic risk during the 2001 dot-com bubble and the 2007-2009 financial crisis.

The purpose of this paper is to empirically explore the impact of "sector-specific" idiosyncratic risk on the systemic risk of the whole financial system. First, this paper examines the magnitude of systemic risk and the marginal risk contribution caused by sectors to the overall systemic risk on the Taiwan stock market. Further, the differences, between VaR of sectors and sector-specific marginal systemic risks, were also compared. Finally, we endeavored to investigate the links between marginal systemic risk caused by a sector-specific anomaly and the impact of global financial crises on Taiwan stock market. It is hoped the results of this study will be a useful tool for those stock investors to accurately identify the true systemic risk of Taiwan stock market and to properly allocate their investment portfolios across sectors according to their true risk contributions. The structure of this paper is as follows. Section II discusses risk contagion theory. Section III describes the methodology used to measure the systemic risk of Taiwan stock market and the implementation of the model, which is designed to solve the research problems. Section IV demonstrates the results of the research and other computation analysis. Finally, section V summarizes some findings and conclusions.

\section{Risk contagion theory and literature regarding sector contribution to the whole system}

\subsection{Drawbacks of VaR}

Value-at-risk (VaR) converts the downside risk of a portfolio into a single number, making it an easy to understand and widely used measure of the risk of financial assets. However, it has been challenged by many recent literatures. Artzner et al. (1999) suggested because VaR was not sub-additive ${ }^{1}$, meaning the VaR of a combined portfolio can be larger than the sum of the VaRs of its components, it was not only incompatible with Markowitz portfolio theory (Markowitz 1952), but also did not suggest diversification reduces risk. Besides, Wong and Fong (2010) proposed since VaR focused on the asset itself in isolation, the real risk of this asset might be underestimated, especially when other assets came under stress. Moreover, Brunnermeier, Crocket, Goodhart, Perssaud, and Shin (2009) suggested because VaR measured a single asset's risk in isolation and did not consider the interconnected effect among assets, it might not necessarily reflect systemic risk, which is the risk when the stability of the whole financial system is threatened. Based on these criticisms, it is doubtful whether VaR is a good risk measure.

Nowadays, many international investors have major stakes in overseas markets to pursue higher profit opportunities. Given the economic success in the last two decades,

\footnotetext{
${ }^{1}$ A risk measure $\rho()$ is subadditive, if, for any two financial assets $A$ and $B, \rho(A+B)$ is no greater than $\rho(\mathrm{A})+\rho(\mathrm{B})$. Sub-additivity: $\rho(\mathrm{X}+\mathrm{Y}) \leq \rho(\mathrm{X})+\rho(\mathrm{Y})$, for any risks $\mathrm{X}, \mathrm{Y}$, lack of sub-additivity (Artzner et al. (1999), Mathematical Finance)
} 
Taiwan stock market has attracted considerable global investments and the most used instrument is investment in Taiwan stock index, such as the MSCI Taiwan Index. Measuring and monitoring the true risk of Taiwan stock market has become a critical issue for investors. VaR, focusing on the risk of an individual exposure in isolation, is the most commonly used measure of risk. However, it does not necessarily reflect how much risk a single exposure contributes to the whole system, i.e. systemic risk, when the stability of the whole system is destroyed. It is necessary to employ more interdependent and comprehensive risk measures to capture the true risk of assets, including systemic risk, which is the main cause of financial crises.

\subsection{Risk contagion during the crisis}

Groups of interdependent institutions, defined as sectors, can contribute to systemic risk in two ways, the common exposure effects, and inter-linkages effects. First, a shock from a sector could become systemic because of direct common exposure, meaning a downward shock could affect most of the institutions within the sector simultaneously and thus trigger a systemic crisis in the sector (De Nicolò, Kwast 2002; Hawkesby et al. 2007). Financial globalization assists the capital and financial assets to flow across various markets, which increases systemic risk and links all markets together exposing them to common risk. Second, due to the markedly increased industry integration nowadays, a more and more complicated web of economy activities and transactions implies this integration enhances the inter-linkage effects and exposes the entities of the web to the same risk factors, and that a shock hitting one institution could spread to the others connected to it.

Many financial crises begin with sector-specific distress that then spills over into other sectors. These "sector-specific" caused crises comprise those before 2000, such as the 1987 Black Monday stock market crash and the 1998 Russian crisis, as well as those after 2000 of (1) the 2001 dot-com bubble, resulting in a financial bubble centered on internet-based companies, the so-called burst of the dot-com companies, and finally affecting most markets in the world, and (2) the 2007-2009 financial crisis, which spread from failures of financial institutions in the United States, due primarily to exposure to subprime securities and credit default swaps(CDS), rapidly devolving into a global crisis which led to many bank failures in Europe and sharp value reductions in equities and commodities worldwide (Brady 1988; Rubin et al. 1999; Brunnermeier 2009; Adrian, Shin 2010a, b; Junior et al. 2010; Allen et al. 2009; Embrechts 2000).

Apparently, these cases resulted from a "sector-specific" anomaly and then this "sectorspecific" anomaly transmitted to increase systemic risk, which not only led to the crisis of the local financial system, but also spilled over across most financial markets and harmed the worldwide financial system. Further, as these global financial crises have shown, common exposure effects and inter-linkages effects have played an important role in international systemic risk that could not be diversified away. It highlights the interconnectedness of financial markets nowadays and demonstrates the importance to employ more interdependent and holistic measures that can take into account the interconnected nature of the financial system and evaluate how much the risk of the asset may deteriorate when other related assets become distressed. 


\subsection{CoVaR model}

Systemic risk, as defined, is the risk of collapse of a whole market where the failure of an idiosyncratic distress could cause a cascading failure of the entire system, as opposed to risk only associated with any one individual entity, a group of entities, or a component of the system. Although systemic risk is the most important formal reason for financial crises, it was not until the financial crisis of 1998 that a few studies began to discuss the measures of systemic risk. These studies can be divided into two types, one adopts a top-down approach exploring systemic risk by attributing it to individual contributors, and the other adopts a bottom-up approach gauging marginal systemic risk that an individual entity contributes to the whole system, not decomposing systemic risk into individual contributors and not attempting to add components up to find total systemic risk (Tarashev et al. 2010).

Several studies have used the top-down approach, decomposing the aggregate systemic risk and allocating it to individual contributors according to their expected loss in the event of distress (Praschnik et al. 2001; Hallerbach 2002; Koyluoglu, Stoker 2002; Kurth, Tasche 2003; Glasserman 2005; Acharya et al. 2009; Huang et al. 2009; Tarashev et al. 2010). The advantage of this top-down approach is the sum of the risk attributed to individual risk contributors will exactly equal the overall systemic risk. However, the disadvantage of this approach is it cannot be employed for the conditions where systemic risk is not measured by a fixed set of failure events. Conquering the disadvantage of the top-down approach, few researches have recently begun to employ the bottom-up approach to measure systemic risk. Adrian and Brummermeier (2008) proposed the concept of "CoVaR", defined as the VaR of an asset conditional on some other assets being in distress, to measure the severity of the systemic risk, which is the whole system failure or potential catastrophe conditional on the negative effects caused by an institution-specific or a sector-specific severe calamity. Acharya, Pedersen, Philippon and Richardson $(2009,2010)$ measured the contributions of individual banks to systemic risk and proposed a "tax charge" based on the contribution to systemic risk. Chan-Lau (2008) used a similar approach to study the spillover effects of the CDS spreads of financial institutions in the US, Europe and Japan. Fong et al. (2009) estimated CoVaRs to evaluate the interdependence of financial institutions in Hong Kong. However, these papers emphasized measuring the systemic risk caused by individual institution's anomaly, i.e. "institution-specific" distress, and proposed institutions that were too large to fail were likely to cause risk spillover effects on the system, as well as transmit more systemic risk to the whole system. Nevertheless, according to the definition and the classification of Brunnermeier, Crocket, Goodhart, Perssaud, and Shin (2009), systemic risk includes the risk caused not only by "individual institutions", which are so large ("too big to fail") that they could negatively affect others, but also by a group of institutions, which are so interdependent ("too interconnected to fail") that they are "systemic as part of a herd" which possess similar characteristics and could be affected by common risk factors. The previous studies of "institution-specific" CoVaR only emphasized the "too big to fail" effect, rather than the "too interconnected to fail" effect. However, due to the above mentioned inter-linkage effect and common exposure effect, the failure of 
a group of interconnected institutions, i.e., "sector-specific" distress, would bring down more severely negative effects on the whole system and would be the primary risk contributor of financial crises. However, there is a lack of research discussing the systemic risk caused by the "sector-specific" disaster. This paper focuses on the Taiwan stock market's systemic risk, conditional on "sector-specific" idiosyncratic risk.

\section{Properties of the conditional VaR methodology}

As indicated in the introduction, there are two types of systemic risk measures, the top-down approach estimates systemic risk by attributing it to individuals, while the bottom-up approach focuses directly on the marginal systemic risk which individual contributors attribute to. Amongst the bottom-up approach, the CoVaR model has been proved by Boyson, Stahel and Stulz (2008) and Jorion and Zhang (2009) to be a good method to measure systemic risk using quantile regressions. There are many advantages of using the CoVaR method. First, it provides a method to explore the comprehensive risk spillovers across the entire financial system. Second, it can decompose the marginal risk, $\Delta \mathrm{CoVaR}$, from the total systemic risk. Then, it can help investors pay more attention to the important marginal risk contributory sectors instead of overall systemic risk, i.e., from the macro prudential perspective to micro prudential perspective. Finally, by exploring the risk factors of important marginal contributory sectors on systemic risk, it can help investors monitor the movement of these important risk factors as an early warning signal of overall systemic risk.

This paper adopts the CoVaR method to gauge systemic risk, both CoVaR and $\Delta \mathrm{CoVaR}$, of Taiwan stock market. For the purpose of this study, VaR and CoVaR were generated from functions of a vector of macroeconomic state variables and were estimated by quantile regressions. To clarify, the framework of this study is depicted as following Fig. 1.

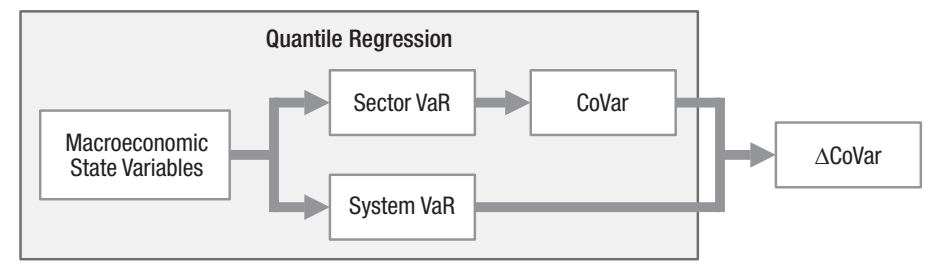

Fig. 1. Study framework

\subsection{VaR, CoVaR and $\Delta$ CoVaR model}

For a given probability and time horizon, VaR is defined as a threshold value such that the probability that the market loss on the portfolio over the given time horizon exceeds this value is exactly the given probability level (Jin, Jorion 2006; Suhobokov 2007). The first step of this paper is to measure the VaRs of the whole Taiwan stock market (denoted as "system VaR") and its component sectors (denoted as "sector VaR") using the historical simulation method because this method provides a simple and straightforward implementation of valuation, as well as no distribution assumption and no complicated 
calculations being required (Suhobokov 2007). In the second step, following the study of Adrian and Brunnermeier (2009), the CoVaR method is employed to evaluate the systemic risk of Taiwan stock market conditional on sector-specific distress. In the following section, $\mathrm{CoVaR}_{i}$ is defined as the system (whole Taiwan stock market, hereafter) VaR conditional on specific sector $i$ being in distress and $\mathrm{CoVaR}_{i}$ was defined as the marginal contribution of sector $i$ to the overall systemic risk which is generated from the difference between the $\mathrm{CoVaR}_{i}$ and the VaR of the whole system.

The distinction between $\mathrm{CoVaR}_{i}$ and $\Delta \mathrm{CoVaR}^{i}$ is the former allows us to study how much the systemic risk will be when conditional on sector-specific's distress, while the latter quantifies how much marginal risk a sector contributes to overall systemic risk. Both VaR and CoVaR measures were computed using the Quantile Regression approach, which was suggested by Koenker and Bassett (1978) to estimate the coefficients. This approach could estimate a specific quantile under a conditional distribution and recently has been successfully used in the analysis of VaR and CoVaR (Chen 2002; Gaglianone et al. 2009; Schaumburg 2010; Coroneo, Veredas 2008; Ou, Yi 2010; Chernozhukov, Umantsev 2001; Chernozhukov, Du 2008).

\subsection{Estimation CoVaR with macroeconomic state variables}

Three steps were used to estimate $\Delta \mathrm{CoVaR}$ with macroeconomic state variables. First, to capture time variation in the joint distribution of a sector's return $\left(X^{i}\right)$ and the whole Taiwan stock market index return $\left(X_{t}^{\text {system }}\right)$, the conditional distribution as a function of state variables is estimated. Subscripted with $t$, the time-varying $X_{t}{ }^{i}$ and $X_{t}{ }^{\text {system }}$ were estimated by conditioning on a vector of 1-month lagged time series for macroeconomic state variables $M_{t-1}$. The following regressions (1) and (2) were run in the monthly data (where " $i$ " denotes a specific sector and "system" denotes the whole system):

$$
\begin{gathered}
X_{t}^{i}=\alpha^{i}+\gamma^{i} M_{t-1}+\varepsilon_{t}^{i}, \\
X_{t}^{\text {system }}=\alpha^{\text {system }}+\gamma^{\text {system }} M_{t-1}+\varepsilon_{t}^{\text {system }} .
\end{gathered}
$$

In addition, to generate the CoVaR conditional on an individual sector, the whole Taiwan stock market index return $\left(X_{t}^{\text {system }}\right)$, regressed as a function of its lag 1 return $\left(X_{t-1}^{\text {system }}\right)$, an individual sector's return $\left(X_{t}{ }^{i}\right)$ and a vector of 1-month lagged time series for macroeconomic state variables $M_{t-1}$, was also estimated in the monthly data:

$$
X_{t}^{\text {system }}=\alpha_{0}^{\text {system } \mid i}+\alpha_{1}^{\text {system } \mid i} X_{t-1}^{\text {system }}+\alpha_{2}^{\text {system } \mid i} X_{t}^{i}+\alpha_{3}^{\text {system } \mid i} M_{t-1}+\varepsilon_{t}^{\text {system } \mid i} .
$$

Second, using the coefficients of the quantile approach from the first step, the predicted values, $\mathrm{VaR}_{t}$ and $\mathrm{CoVaR}_{t}$, were generated from the regressions (4), (5), and (6):

$$
\begin{gathered}
\operatorname{VaR}_{t}^{i}=\alpha^{i}+\gamma^{i} M_{t-1}, \\
\operatorname{VaR}_{t}^{\text {system }}=\alpha^{\text {system }}+\gamma^{\text {system }} M_{t-1}, \\
\operatorname{CoVaR}_{t}^{i}=\alpha_{0}^{\text {system } \mid i}+\alpha_{1}^{\text {system } \mid i} \operatorname{VaR}_{t-1}^{\text {system }}+\alpha_{2}^{\text {system } \mid i} \operatorname{VaR}_{t}^{i}+\alpha_{3}^{\text {system } \mid i} M_{t-1} .
\end{gathered}
$$


Finally, a panel of monthly $\Delta \mathrm{CoVaR}_{t}^{i}$, conditional on a sector " $i$ ", was obtained by subtracting $\mathrm{VaR}_{t}^{\text {system }}$ from $\mathrm{CoVaR}_{t}^{i}$ :

$$
\Delta \mathrm{CoVaR}_{t}^{i}=\mathrm{CoVaR}_{t}^{i}-\mathrm{VaR}_{t}^{\text {system }} .
$$

When estimating the above-mentioned time-varying CoVaR and $\mathrm{VaR}_{t}$, the set of lagged macroeconomic state variables $M_{t-1}$ was used as controlling variables to remove variation which was not directly related to the risk of the financial system (Aktan et al. 2010). These macroeconomic state variables were usually used to describe the "state" of the dynamic system and to forecast the future behavior of the system. Many studies have suggested the aggregate stock market return predictability is highly related to macroeconomic state variables that could reflect the business cycle (Chen et al. 1986; Fama, French 1993; Vassalou 2003; Petkova 2006; Ludvigson, Ng 2007; Birz, Lott 2008; Cenesizoglu, Timmermann 2008; Li, Liu 2010; Festic et al. 2009). In reference to these researches, the selected macroeconomic state variables and reasons to be chosen are listed as below:

1) Short term "Credit spread": which was defined as the difference between the rate of a government bond and the rate of commercial paper in Taiwan money market.

2) Monetary Aggregate M1B: which equalled M1A plus Passbook savings deposits of Individuals and non-profit organizations in banks and community financial institutions.

3) Unemployment rate: the unemployment rate and Taiwan stock return were found to be stable time series after difference and to have a long-term equilibrium.

4) The GDP leading index: which is composed of seven sub-indicators and is widely used in the financial field, because it is a significant indicator of Taiwan stock market returns.

5) Exchange rate movement: which plays an important role in Taiwan economic performance and in the short run has significantly negative influences on Taiwan stock returns.

6) The Crude Oil price movements: which has similar impacts as exchange rate movements and in the short run has a significantly negative influence on Taiwan Stock returns.

7) NASDAQ index return: which has been proved to be the most influential external source on Taiwan stock market.

Besides, Taiwan is one of the Four Asian Dragons and its stock market has attracted a large number of investors' attention owing to its rapid economic growth over the past decades. Since it is highly correlated with international capital markets and other Asian stock markets, Taiwan stock market could provide pricing predication or hedging tools for other Asian stock markets (Sheu, Cheng 2011). This analysis, taking Taiwan stock market as example, focused on the VaR and $\triangle \mathrm{CoVaR}$ of this stock market index and its components of 18 sector indices, which are denoted as following Table 1. 
Table 1. Variable definition

Whole stock market VaR: $X^{\text {system }}$ : Taiwan stock index

\begin{tabular}{lll}
\hline Sector VaR: & & \\
\hline$X^{1}:$ cement sector & $X^{7}:$ medical technique sector & $X^{13}:$ electronic sector \\
\hline$X^{2}:$ food sector & $X^{8}:$ ceramic sector & $X^{14}:$ building sector \\
\hline$X^{3}:$ plastic sector & $X^{9}:$ papermaking sector & $X^{15}:$ shipping sector \\
\hline$X^{4}:$ textile fiber sector & $X^{10}:$ steel sector & $X^{16}:$ sightseeing sector \\
\hline$X^{5}:$ electrical machinery sector & $X^{11}:$ rubber sector & $X^{17}:$ banking sector \\
\hline$X^{6}:$ electric appliance sector & $X^{12}:$ automobile sector & $X^{18}:$ trade sector \\
\hline
\end{tabular}

Data was collected from January 2001 through September 2010, covering the dot-com bubble of 2001 as well as the financial crisis of 2007-2009, containing a whole economic cycle of Taiwan.

\section{Empirical results}

This section presents the empirical results of applying the CoVaR method using the quantile approach introduced in the previous section to explore the systemic risk measures of Taiwan stock market. First, the results of quantile regressions for sector's returns $\left(X^{i}\right)$ and whole system return $\left(X^{\text {system }}\right)$ on the macroeconomic state variables were calculated. Second, VaRs of the whole Taiwan stock market (system VaR, VaR ${ }^{\text {system }}$ ) and individual sectors (sector $\mathrm{VaR}, \mathrm{VaR}^{i}$ ) on isolation were estimated. Third, systemic CoVaR measures conditional on individual sectors, $\mathrm{CoVaR}^{i}$, were generated. In addition, two risk measures of unconditional and conditional on sectors' being in distress, i.e., $\mathrm{VaR}^{\text {system }}$ and $\mathrm{CoVaR}^{i}$, were compared. Further, the difference between these two risk measures, denoted as $\Delta \mathrm{CoVaR}^{i}$, was generated to capture the marginal contribution of an individual sector to overall systemic risk. Finally, the links between $\Delta \mathrm{CoVaR}^{i}$ of some important sectors and the recent global financial crises were also investigated.

\subsection{VaR estimation}

The coefficients of quantile regressions for sector returns $\left(X^{i}\right)$ and whole system return $\left(X^{\text {system }}\right)$ of Taiwan stock market on macroeconomic state variables were estimated. Using these equations, the VaR of Taiwan Stock Index (VaR $\left.{ }^{\text {system }}\right)$ and VaRs of 18 sector indices $\left(\mathrm{VaR}^{1}\right.$ to $\left.\mathrm{VaR}^{18}\right)$, were shown in Table 2, calculated by the Historical Simulation Method at $1 \%, 5 \%$, and $10 \%$ maximum loss probability and denoted as VaR $1 \%$, VaR $5 \%$, and $\mathrm{VaR} 10 \%$, respectively.

As seen in Table 2, VaR increased when the maximum loss probability decreased. The trade sector, building sector, electric appliance sector, electronic sector, and electrical machinery sector had the top $5 \mathrm{VaR}$ measures at any confidence level. For example, at $1 \%$ maximum loss probability, the VaR of electronic sector and Taiwan stock index were -0.06697 and -0.06026 , respectively, and the sector indices with the largest and smallest VaR were trade sector of -0.11382 , and food sector of -0.04110 . 
Table 2. VaR of stock index \& sector index at $1 \%, 5 \%$ and $10 \%$ respectively

\begin{tabular}{|c|c|c|c|}
\hline & VaR $1 \%$ & VaR 5\% & VaR $10 \%$ \\
\hline $\begin{array}{l}\text { Whole stock market VaR: } \\
X^{\text {system }} \text { : Taiwan stock index }\end{array}$ & -0.06026 & -0.05220 & -0.04500 \\
\hline \multicolumn{4}{|l|}{ Sector VaR: } \\
\hline$X^{1}:$ cement sector & -0.04618 & -0.04035 & -0.03358 \\
\hline$X^{2}:$ food sector & -0.04110 & -0.03454 & -0.02745 \\
\hline$X^{3}:$ plastic sector & -0.04990 & -0.04423 & -0.03759 \\
\hline$X^{4}:$ textile fiber sector & -0.05595 & -0.05107 & -0.04493 \\
\hline$X^{5}:$ electrical machinery sector & -0.06359 & -0.05619 & -0.04484 \\
\hline$X^{6}:$ electric appliance sector & -0.07182 & -0.06500 & -0.05835 \\
\hline$X^{7}:$ medical technique sector & -0.05791 & -0.04820 & -0.03707 \\
\hline$X^{8}:$ ceramic sector & -0.05585 & -0.04868 & -0.03653 \\
\hline$X^{9}:$ papermaking sector & -0.05870 & -0.05285 & -0.04754 \\
\hline$X^{10}:$ steel sector & -0.04850 & -0.04401 & -0.03587 \\
\hline$X^{11}:$ rubber sector & -0.04465 & -0.03902 & -0.02971 \\
\hline$X^{12}:$ automobile sector & -0.04603 & -0.04406 & -0.03886 \\
\hline$X^{13}:$ electronic sector & -0.06697 & -0.05941 & -0.05006 \\
\hline$X^{14}:$ building sector & -0.10082 & -0.08487 & -0.07066 \\
\hline$X^{15}:$ shipping sector & -0.05516 & -0.04740 & -0.04014 \\
\hline$X^{16}:$ sightseeing sector & -0.04912 & -0.04529 & -0.03626 \\
\hline$X^{17}$ : banking sector & -0.05932 & -0.05204 & -0.04604 \\
\hline$X^{18}:$ trade sector & -0.11382 & -0.09169 & -0.05992 \\
\hline
\end{tabular}

The sector VaR is a risk measure representing the loss due to the sector's being in distress in isolation. However, the question of whether a sector with bigger VaR could mean it would contribute more marginal risk to the whole system needed to be further investigated and is discussed in the following.

\subsection{CoVaR estimation}

To generate the CoVaR measures, the quantile CoVaR regressions, as shown in equation (6) of section 3.2, conditional on individual sectors were established and the coefficients of regressions were estimated under the OLS method, $10^{\text {th }}$ quantile method, and $5^{\text {th }}$ quantile method respectively. Under these estimated equations, the CoVaRs for the whole system conditional on 18 sectors $\left(\mathrm{CoVaR}^{1}\right.$ to $\left.\mathrm{CoVaR}^{18}\right)$ at $1 \%, 5 \%$, and $10 \%$ maximum loss probability were then generated independently. To simplify the discussion, CoVaR at 5\% maximum loss probability was chosen to be shown in Table 3 . As indicated in the table, CoVaRs measured using the OLS method were significantly larger 
Table 3. Predicted CoVaR(5\%) of Taiwan stock sector index using OLS, Quantile 5\% and Quantile 10\%

\begin{tabular}{lccc}
\hline & & Method & \\
\hline CoVaR $(5 \%)$ when conditional on: & OLS & Quantile $10^{\text {th }}$ & Quantile $5^{\text {th }}$ \\
\hline$X^{1}:$ cement sector & -0.0324 & -0.0697 & -0.07347 \\
\hline$X^{2}:$ food sector & -0.0307 & -0.055 & -0.07365 \\
\hline$X^{3}:$ plastic sector & -0.0259 & -0.0486 & -0.07395 \\
\hline$X^{4}:$ textile fiber sector & -0.0318 & -0.0532 & -0.07313 \\
\hline$X^{5}:$ electrical machinery sector & -0.0286 & -0.05 & -0.07932 \\
\hline$X^{6}:$ electric appliance sector & -0.0306 & -0.0657 & -0.07558 \\
\hline$X^{7}:$ medical technique sector & -0.033 & -0.0555 & -0.06575 \\
\hline$X^{8}:$ ceramic sector & -0.0204 & -0.0524 & -0.0545 \\
\hline$X^{9}:$ papermaking sector & -0.0311 & -0.0627 & -0.07268 \\
\hline$X^{10}:$ steel sector & -0.0224 & -0.0515 & -0.06374 \\
\hline$X^{11}:$ rubber sector & -0.0326 & -0.0677 & -0.0702 \\
\hline$X^{12}:$ automobile sector & -0.026 & -0.0581 & -0.05916 \\
\hline$X^{13}:$ electronic sector & -0.035 & -0.0629 & -0.09508 \\
\hline$X^{14}:$ building sector & -0.033 & -0.0634 & -0.07175 \\
\hline$X^{15}:$ shipping sector & -0.0227 & -0.0478 & -0.06337 \\
\hline$X^{16}:$ sightseeing sector & -0.0306 & -0.0474 & -0.06782 \\
\hline$X^{17}:$ banking sector & -0.0316 & -0.0623 & -0.07999 \\
\hline$X^{18}:$ trade sector & -0.0147 & -0.0542 & -0.06475 \\
\hline & & & \\
\hline
\end{tabular}

than those estimated by the quantile model and CoVaRs of the quantile method at the $5^{\text {th }}$ quantile were larger than those of the $10^{\text {th }}$ quantile. Besides, regardless of what model was used, the two highest CoVaRs of Taiwan stock market could occur when it was conditional on the electronic sector and banking sector being at their VaR levels.

Combining Table 2 and 3, the top 5 highest VaR sectors (trade sector, building sector, electric appliance sector, electronic sector, and electrical machinery sector) did not completely equal the top 5 highest risk contributory sectors to the system CoVaR (electronic sector, banking sector, electrical machinery sector, electric appliance sector, plastic sector). Amongst these sectors, the electronic sector had the highest sector VaR and the highest systemic $\mathrm{CoVaR}$, however, the banking sector did not have relatively substantial sector VaR, but did have the 2nd highest systemic CoVaR. On the contrary, the trade sector and building sector possessed the two highest sector VaRs, but they did not have relatively high systemic CoVaR. It appears sector VaR is not necessarily correlated with systemic CoVaR, with a Pearson's correlation of only 0.2715 . The reason for this 
mismatch could be the probability sector $\mathrm{VaR}$ is not the only risk that transmits to the system and these two risk measures apparently capture different risks of the system. Thus, merely using VaR to measure risk would be insufficient and might underestimate its true risk. Up to this point, these results are consistent with those of Adrian, Tobias and Markus Brunnermeier (2008).

Correlation between $\operatorname{VaR}^{i}$ and $\mathrm{CoVaR}^{i}$ :

\begin{tabular}{cc}
\hline & $\operatorname{VaR}^{i}$ \\
\hline $\mathrm{CoVaR}^{i}$ & 0.2715 \\
\hline
\end{tabular}

Fig. 2 depicts the measures of sector VaR(solid line) and systemic CoVaR(dotted line) of all 18 sectors. Clearly, most conditional CoVaRs were larger than the sector's VaR, except for a few sectors. In addition, it showed a sector with higher VaR did not necessarily contribute more systemic risk to the whole system or lead to a higher CoVaR.

In addition, as the electronic sector and banking sector rank as the top two CoVaR sectors, their time series CoVaRs for the sample period needed to be thoroughly explored, with this being presented in Fig. 3. The CoVaRs of these two sectors was apparently spilt at 2007, matching the time of the global financial crises. Owing to the 2001 dotcom bubble, the electronic sector (as dotted line) had a larger CoVaR than the banking sector (solid line) from 2003 to 2007. On the contrary, for the 2007-2009 financial crisis, the banking sector has had a higher CoVaR measure than electronic sector from 2007 till now, particularly in 2007.

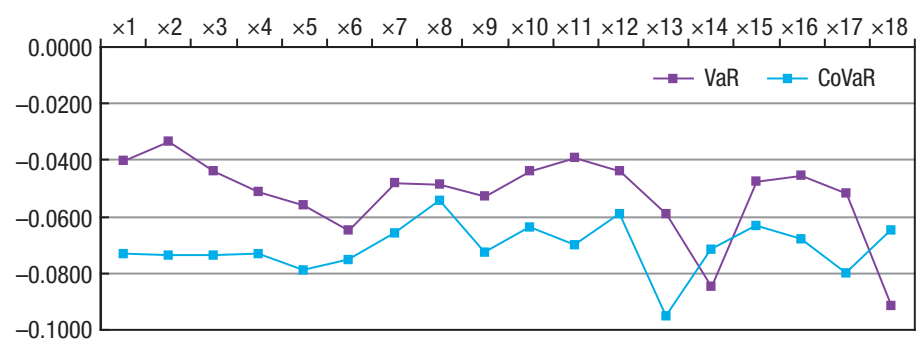

Fig. 2. Sector VaR and CoVaR conditional on 18 sectors

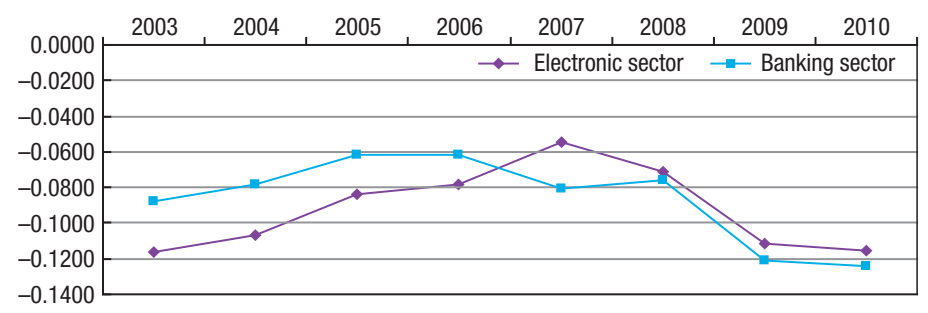

Fig. 3. Sector CoVaR of electronic sector and banking sector during 2003-2010 


\subsection{Marginal contribution to systemic risk, $\triangle \mathrm{CoVaR}$}

The difference between $\mathrm{CoVaR}$ and $\mathrm{VaR}$ measures, denoted as $\Delta \mathrm{CoVaR}$, was generated to capture the marginal contribution of an individual sector to overall systemic risk. The $\Delta$ CoVaR of Taiwan stock index using OLS, Quantile $5^{\text {th }}$ and Quantile $10^{\text {th }}$ at $1 \%$, $5 \%$, and $10 \%$ maximum loss probability were calculated corresponsively and only the $\Delta \mathrm{CoVaR}$ at $5 \%$ maximum loss probability and under the $5^{\text {th }}$ quantile percentile was listed on Table 4 and depicted in Fig. 4. Similar to the result of CoVaR, ranking as the top 2 largest transaction volume sectors in Taiwan stock market, the electronic sector and banking sector also possessed the top 2 highest marginal risk contribution, $\Delta \mathrm{CoVaR}$, for Taiwan stock market, indicating conditional on the crisis of these two sectors, the systemic risk of the whole Taiwan stock market could dramatically increase. This result could simultaneously prove the "too big to fail" and "too interconnected to fail" effects of the financial system characteristics which could not be fully obtained from the result of the VaR measure.

To clearly compare $\mathrm{VaR}^{i}$ with $\Delta \mathrm{CoVaR}^{i}$, Table 5 lists the paired value of these two risk measures for 18 sectors. From the table, while the trade sector, building sector, electrical appliance sector, electronic sector, and electrical machinery sector ranked as the top 5 highest VaR sectors, the electronic sector and banking sector were the 2 most marginal

Table 4. $\Delta \operatorname{CoVaR}(5 \%)$ of Taiwan stock index using Quantile $5^{\text {th }}$

\begin{tabular}{lc|lc}
\hline \multicolumn{1}{c}{ Conditional on: } & $\Delta \mathrm{CoVaR}^{i}$ & \multicolumn{1}{|c}{ Conditional on: } & $\Delta \mathrm{CoVaR}^{i}$ \\
\hline$X^{1}:$ cement sector & -0.0213 & $X^{10}:$ steel sector & -0.0115 \\
\hline$X^{2}:$ food sector & -0.0215 & $X^{11}:$ rubber sector & -0.0180 \\
\hline$X^{3}:$ plastic sector & -0.0217 & $X^{12}:$ automobile sector & -0.0070 \\
\hline$X^{4}:$ textile fiber sector & -0.0209 & $X^{13}:$ electronic sector & -0.0429 \\
\hline$X^{5}:$ electrical machinery sector & -0.0271 & $X^{14}:$ building sector & -0.0195 \\
\hline$X^{6}:$ electric appliance sector & -0.0234 & $X^{15}:$ shipping sector & -0.0112 \\
\hline$X^{7}:$ medical technique sector & -0.0136 & $X^{16}:$ sightseeing sector & -0.0156 \\
\hline$X^{8}:$ ceramic sector & -0.0023 & $X^{17}:$ banking sector & -0.0278 \\
\hline$X^{9}:$ papermaking sector & -0.0205 & $X^{18}:$ trade sector & -0.0126 \\
\hline
\end{tabular}

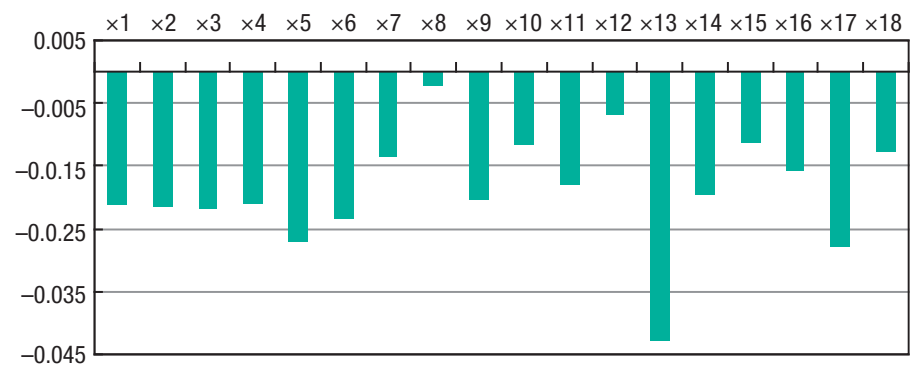

Fig. 4. $\Delta \mathrm{CoVaR}$ of 18 sectors 
Table 5. Yearly pairs of $\operatorname{VaR}^{i}$ and $\Delta \mathrm{CoVaR}^{i}$ for 18 sectors

\begin{tabular}{lcc|lcr}
\hline \multicolumn{1}{c}{ sector } & $\mathrm{VaR}^{i}$ & $\Delta \mathrm{CoVaR}^{i}$ & \multicolumn{1}{c}{ sector } & $\mathrm{VaR}^{i}$ & $\Delta \mathrm{CoVaR}^{i}$ \\
\hline$X^{1}:$ cement sector & -0.04035 & -0.0213 & $X^{10}:$ steel sector & -0.04401 & -0.0115 \\
\hline$X^{2}:$ food sector & -0.03454 & -0.0215 & $X^{11}:$ rubber sector & -0.03902 & -0.0180 \\
\hline$X^{3}:$ plastic sector & -0.04423 & -0.0217 & $X^{12}:$ automobile sector & -0.04406 & -0.0070 \\
\hline$X^{4}:$ textile fiber sector & -0.05107 & -0.0209 & $X^{13}$ : electronic sector & -0.05941 & -0.0429 \\
\hline$X^{5}:$ electrical machinery & -0.05619 & -0.0271 & $X^{14}$ : building sector & -0.08487 & -0.0195 \\
sector & & & & & \\
\hline $\begin{array}{l}X^{6}: \text { electric appliance } \\
\text { sector }\end{array}$ & -0.06500 & -0.0234 & $X^{15}$ : shipping sector & -0.04740 & -0.0112 \\
\hline$X^{7}:$ medical technique & -0.04820 & -0.0136 & $X^{16}:$ sightseeing sector & -0.04529 & -0.0156 \\
sector & & & & & \\
\hline$X^{8}:$ ceramic sector & -0.04868 & -0.0023 & $X^{17}:$ banking sector & -0.05204 & -0.0278 \\
\hline$X^{9}:$ papermaking sector & -0.05285 & -0.0205 & $X^{18}:$ trade sector & -0.09169 & -0.0126 \\
\hline
\end{tabular}

risk contributing sectors for Taiwan stock market. The main conclusions here are sectors might have a low VaR but a high $\Delta \mathrm{CoVaR}$, and $\Delta \mathrm{CoVaR}$ could capture not only systemic risk but also the individual sector risk.

The financial crises of the 2001 dot-com bubble and 2007-2009 financial crisis resulted from systemic risk which not only led to the crisis of the local financial system, but also damaged the world-wide financial system. Taiwan is a primary electronic product factory of the world and its banking sector plays an important role in Pacific Asia. Thus, these two global financial crises might affect the electronic and banking sectors of Taiwan stock market. Is there any link between the global financial crises and $\Delta \mathrm{Co}-$ VaR? The time series $\Delta \mathrm{CoVaR}^{i}$ of electronic sector, banking sector and market average during 2003 to 2010 was showed on Table 6 and depicted as Fig. 5. For the recovery from the 2001 dot-com bubble, the $\triangle \mathrm{CoVaR}$ of the electronic sector (blue line) is get-

Table 6. Time series $\triangle \mathrm{CoVaR}$ of Electronic Sector, Banking Sector, and Market Average during 2003-2010

\begin{tabular}{cccc}
\hline & Electronic Sector & Banking Sector & Market Average \\
\hline 2003 & -0.0475 & -0.0141 & -0.0372 \\
\hline 2004 & -0.0451 & -0.0174 & -0.0325 \\
\hline 2005 & -0.0425 & -0.0216 & -0.0297 \\
\hline 2006 & -0.0405 & -0.0284 & -0.0253 \\
\hline 2007 & -0.0319 & -0.0331 & -0.0309 \\
\hline 2008 & -0.0233 & -0.0303 & -0.0235 \\
\hline 2009 & -0.0155 & -0.0199 & -0.0177 \\
\hline 2010 & -0.0125 & -0.0170 & -0.0154 \\
\hline
\end{tabular}




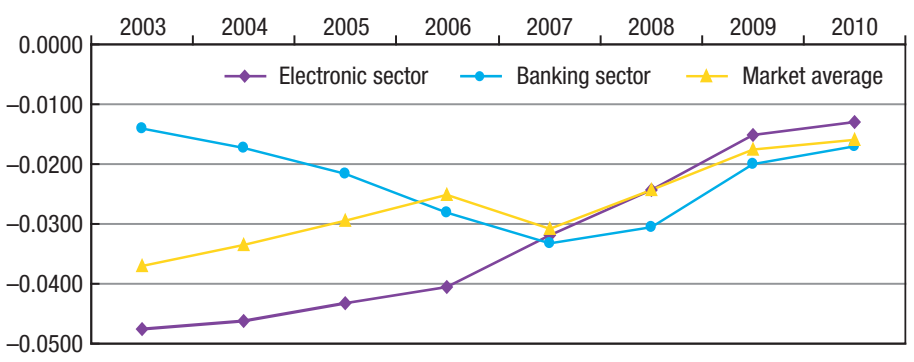

Fig. 5. $\Delta \mathrm{CoVaR}^{i}$ of electronic sector, banking sector and market average during 2003 to 2010

ting smaller from 2003 to 2010 . However, the banking sector was seriously affected by the 2007-2008 financial crisis, and its $\Delta \mathrm{CoVaR}$ was largest during these periods. The market average $\Delta \mathrm{CoVaR}$ of the 18 sectors was largest at the beginning of the sample period and 2007, indicating Taiwan stock market deteriorated during the dot-com bubble and the 2007-2008 financial crisis, and $\Delta$ CoVaR could capture these characteristics.

\section{Conclusion}

Many financial crises have resulted from systemic risk that was initially brought by idiosyncratic distress, spilling over across the related entities and finally causing a crunch of the entire system. The interaction between financial distress and systemic risk from the effect of idiosyncratic distress has been discussed recently. Amongst the idiosyncratic distress, sector-specific risk caused by a group of interconnected institutions has been accused of being the main reason for the increase in systemic risk, which led to the formalization of financial crises. As illustrated previously, VaR focuses on the asset itself in isolation, thus it seems negligible to capture the systemic risk especially when other assets come under stress.

In this research, Taiwan stock market was taken as an example and data were collected from 2000 to 2010, which contained the 2001 dot-com bubble and the 2007-2009 financial crisis. Following the CoVaR method of Adrian, Tobias, and Markus Brunnermeier (2010), this research attempted to empirically explore the impact of sectorspecific idiosyncratic risk on the systemic risk of the entire financial system and tried to examine the link between financial crises, systemic risk, and the idiosyncratic risk of a sector-specific anomaly.

As defined, CoVaR is the system VaR conditional on specific sector being in distress and $\triangle \mathrm{CoVaR}$ is the marginal contribution of individual sector to the overall systemic risk. Both CoVaR and $\triangle \mathrm{CoVaR}$ were used to measure systemic risk in this paper.

Our empirical results are summarized as following. The results of the present study might be summarized by pointing out the following. First, the top 5 highest VaR sectors did not completely equal the top 5 highest risk contributory sectors to the system CoVaR. This showed there was no significant relationship between sector VaR and CoVaR, which was supported by a low correlation coefficient of 0.2715 . The reason is that the sector VaR and CoVaR captured different risk characteristics. The former accessed the 
risk of a sector in isolation, however, the latter appraised the systemic risk conditional on a specific sector being at its VaR level. Second, ranking as the top 2 largest transaction volume sectors in Taiwan stock market, the electronic sector and banking sector also possessed the top 2 highest marginal risk contributions, $\Delta \mathrm{CoVaR}$. This result could simultaneously prove the "too big to fail" and "too interconnected to fail" effects of financial system characteristics, which could not be fully obtained from the result of the VaR measure. Finally, linking the $\Delta \mathrm{CoVaR}$ measure to the global financial crises, $\triangle \mathrm{CoVaR}$ perfectly explained Taiwan stock market disturbance during the 2001 dot-com bubble and 2007-2008 financial crisis, both of which were resulted from systemic risk initially brought by a sector-specific idiosyncratic distress, finally causing the crunch of the whole system. It showed the financial crises, systemic risk, and the idiosyncratic risk of sector-specific are all linked.

This study has taken a successful step in the direction of measuring the marginal contribution risk of sector-specific effects on Taiwan stock market. The finding is important for investors by suggesting that the marginal risk contribution, $\Delta \mathrm{CoVaR}$, is more essential as an estimator of the risk of financial assets and is a useful measure to monitor financial risk. When addressing the value of risk of an asset, the investors should focus not only on its own risk but also on the risk propagated from the system. $\triangle \mathrm{CoVaR}$ could empirically assist investors to identify systemic risk from a macro into a micro prudential perspective. First, by integrating the monitoring of system VaR with sectorspecific $\triangle \mathrm{CoVaR}$, the investors could shift attention from the VaR of overall system risk to the larger marginal risk contribution of the individual sector, which is called "the systemic importance sector" and which is usually resulted from "too big to fail" or "too interconnected to fail" effects. When the systemic importance sector's $\Delta$ CoVaR increases which accompanied with an ascending market average, it provides investors a warning signal that the whole financial system is faced with increasing systemic risk from the systemic importance sector. Moreover, when the sector's $\Delta$ CoVaR increases continuously and is larger than the market average, it is more likely that the systemic importance sector would be in distress and could further lead to a crunch for the entire system. For example, demonstrated on table 5 and Fig. 4, $\Delta \mathrm{CoVaR}$ of banking sector deteriorated gradually from 2003 of -0.0141 , arrived at the peak on 2007 of -0.0331 which exceeded that of market average of -0.0309 , and then mitigated from 2007 to 2010 of -0.017 . The period of 2003 to 2010 could be divided into 3 sub-periods which contain different information for investors to practically create and manage their portfolios. During 2003 to 2006, the ascending $\Delta$ CoVaRs of both banking sector and market average could be regarded as warning signals of increasing distress pressure on systemic risk from banking sector. During 2007, the highest $\Delta$ CoVaR of banking sector exceeded market average and the 2007-2008 financial crisis exactly broke out at the same time. During 2008 to 2010 , the descending $\triangle$ CoVaRs of both banking sector and market average could be explained as the marginal contributory risk from banking sector had been gradually fading away. In addition, the descending $\Delta \mathrm{CoVaRs}$ of electronic sector during 2003 of -0.0475 to 2010 of -0.0125 could also be regarded as the marginal contributory risk had been gradually diminishing. Second, by identifying the influential risk indicators of systemic importance sectors, the investors could focus on the impor- 
tant sectors and scrutinize their risk indicators, which can be regarded as early warning signals for the systemic importance sectors and for the entire financial system. Taking liquidity of financial assets as well as default ratio of loan assets, the most important influential risk indicators on $\triangle \mathrm{CoVaR}$ of banking sector, as an example, the 2007-2008 financial crisis spread from failures of financial institutions due primarily to the serious rising default ratio of subprime and the collapse of liquidity on financial assets. When any these risk indicators become unfavorable beforehand, $\triangle \mathrm{CoVaR}$ of banking sector could soar afterward and this increasing systemic risk could even cause a crunch of the entire system. For investors, it is necessary to identify and scrutinize these early warning signals and take appropriate actions, in advance, to avoid or mitigate the potential losses from either the distress of the systemic importance sector or the catastrophe of the whole market system.

It is recommended the approach outlined in this study be replicated in other stock markets or other financial assets. Moreover, it would be increasingly crucial to explore the influential indicators of the $\triangle \mathrm{CoVaR}$ to predict in advance the marginal risk contribution based on the movement of the risk factors. However, because our sample market is very small compared with international stock markets, and the data period is relatively short, it is possible that other stock markets may have different results.

\section{References}

Acharya, V.; Pedersen, L.; Philippon, T.; Richardson, M. 2009. Measuring systemic risk, Technical Report. New York University.

Acharya, V.; Pedersen, L.; Philippon, T.; Richardson, M. 2010. A tax on systemic risk, Quantifying Systemic Risk (forthcoming).

Adrian, T.; Brunnermeier, M. 2008. CoVaR, Working Paper. Federal Reserve Bank of New York. Adrian, T.; Shin, H. S. 2010a. The changing nature of financial intermediation and the financial crisis of 2007-2009, Annual Review of Economics 2: 603-618.

http://dx.doi.org/10.1146/annurev.economics.102308.124420

Adrian, T.; Shin, H. S. 2010b. Liquidity and leverage, Journal of Financial Intermediation 19: 418-437. http://dx.doi.org/10.1016/j.jfi.2008.12.002

Aktan, B.; Korsakienè, R.; Smaliukiene, R. 2010. Time-varying volatility modelling of Baltic stock markets, Journal of Business Economics and Management 11: 511-532.

http://dx.doi.org/10.3846/jbem.2010.25

Allen, F.; Babus, A.; Carletti, E. 2009. Financial crises: theory and evidence, Working Paper. University of Pennsylvania.

Ang, A.; Xing, R.; Zhang, Y. 2006. The cross-section of volatility and expected returns, Journal of Finance 61: 259-299. http://dx.doi.org/10.1111/j.1540-6261.2006.00836.x

Artzner, P.; Delbaen, F.; Eber, J. M.; Heath, D. 1999. Coherent measures of risk, Mathematical Finance 9: 203-228. http://dx.doi.org/10.1111/1467-9965.00068

Bekaert, G.; Harvey, C. R. 1997. Emerging equity market volatility, Journal of Financial Economics 43: 29-77. http://dx.doi.org/10.1016/S0304-405X(96)00889-6

Birz, G.; Lott, J. R. 2008. The effect of macroeconomic news on stock returns: new evidence from newspaper coverage, Working Paper. State University of New York.

Boyson, N.; Stahel, C.; Stulz, R. 2008. Hedge fund contagion and liquidity, Working Paper. Northeastern University. 
Brady, N. F. 1988. Report of the presidential task force on market mechanisms, U.S. Government Printing Office.

Brunnermeier, M. 2009. Deciphering the liquidity and credit crunch 2007-2008, Journal of Economic Perspectives 23: 77-100. http://dx.doi.org/10.1257/jep.23.1.77

Brunnermeier, M.; Crockett, A.; Goodhart, C.; Persaud, A. D.; Shin, H. 2009. The fundamental principles of financial regulation, Geneva Reports on the World Economy 11.

Campbell, J.; Hilscher, J.; Szilagyi, J. A. 2008. In search of distress risk, Journal of Finance 63: 2899-2939. http://dx.doi.org/10.1111/j.1540-6261.2008.01416.x

Cenesizoglu, T.; Timmermann, A. G. 2008. Is the distribution of stocks returns predictable?, Working Paper. HEC Montreal.

Chan-Lau, J. A. 2008. Default risk codependence in the global financial system: was the Bear Stearns bailout justified?, Working Paper. International Monetary Fund.

Chen, M. Y.; Chen, J. E. 2002. Application of quantile regression to estimation of value at risk, Review of Financial Risk Management 1: 1-15.

Chen, N. F.; Roll, R.; Ross, S. A. 1986. Economic forces and the stock market, Journal of Business 59: 383-403. http://dx.doi.org/10.1086/296344

Chernozhukov, V.; Du, S. 2008. Extremal quantiles and Value-at-Risk, in The New Palgrave Dictionary of Economics. 2nd edition.

Chernozhukov, V.; Umantsev, L. 2001. Conditional Value-at-Risk: aspects of modeling and estimation, Empirical Economics 26: 271-292. http://dx.doi.org/10.1007/s001810000062

Coroneo, L.; Veredas, D. 2008. Intradaily seasonality of returns distribution: a quantile regression approach and intradaily VaR estimation, Working Paper. Universite Libre de Bruxelles.

De Nicolò, G.; Kwast, M. 2002. Systemic risk and financial consolidation: are they related?, Journal of Banking and Finance 26: 861-880. http://dx.doi.org/10.1016/S0378-4266(02)00211-X Embrechts, P. 2000. Extreme value theory: potential and limitations as an integrated risk management tool, Derivatives Use, Trading and Regulation 6: 449-456.

Fama, E. F.; French, K. R. 1993. Common risk factors in the returns on stocks and bonds, Journal of Financial Economics 33: 3-56. http://dx.doi.org/10.1016/0304-405X(93)90023-5

Festic, M.; Repina, S.; Kavkler, A. 2009. The overheating of five EU new member states and cyclicality of systemic risk in the banking sector, Journal of Business Economics and Management 10: 219-232. http://dx.doi.org/10.3846/1611-1699.2009.10.219-232

Fong, T. P. W.; Fung, L. K. P.; Lam, L. L. F.; Yu, I. W. 2009. Measuring the interdependence of banks in Hong Kong, Working Paper. Hong Kong Monetary Authority.

Fu, F. 2009. Idiosyncratic risk and the cross-section of expected stock returns, Journal of Financial Economics 91: 24-37. http://dx.doi.org/10.1016/j.jfineco.2008.02.003

Gaglianone, W. P.; Lima, L. R.; Linton, O.; Smith, D. R. 2011. Evaluating Value-at-Risk models via quantile regression, Journal of Business and Economic Statistics 29: 150-160.

http://dx.doi.org/10.1198/jbes.2010.07318

Glasserman, P. 2005. Measuring marginal risk contributions in credit portfolios, Journal of Computational Finance 9: 1-41.

Goetzmann, W.; Li, L.; Rouwenhorst, G. 2005. Long-term global market correlations, Journal of Business 78: 1-38. http://dx.doi.org/10.1086/426518

Gokcan, S. 2000. Forecasting volatility of emerging stock markets: linear versus non-linear GARCH models, Journal of Forecasting 19: 499-504.

http://dx.doi.org/10.1002/1099-131X(200011)19:6<499::AID-FOR745>3.0.CO;2-P

Hallerbach, W. 2002. Decomposing portfolio Value-at-Risk: a general analysis, Journal of Risk 5: $1-18$. 
Hawkesby, C.; Marsh, I.; Stevens, I. 2007. Comovements in the equity prices of large complex financial institutions, Journal of Financial Stability 2: 391-411.

http://dx.doi.org/10.1016/j.jfs.2006.12.001

Huang, X.; Zhou, H.; Zhu, H. 2009. A framework for assessing the systemic risk of major financial institutions, Journal of Banking and Finance 33: 2036-2049.

http://dx.doi.org/10.1016/j.jbankfin.2009.05.017

Jin, Y.; Jorion, P. 2006. Firm value and hedging: evidence from the US oil and gas producers, Journal of Finance 61: 893-919. http://dx.doi.org/10.1111/j.1540-6261.2006.00858.x

Jorion, P.; Zhang, G. 2009. Credit contagion from counterparty risk, Journal of Finance 64: 2053-2087. http://dx.doi.org/10.1111/j.1540-6261.2009.01494.x

Junior, L. S. 2011. Correlation of financial markets in times of crisis, Working Paper. Instituto de Ensino e Pesquisa.

Koenker, R.; Bassett, G. W. 1978. Regression quantiles, Econometrica 46: 33-50.

http://dx.doi.org/10.2307/1913643

Koyluoglu, H. U.; Stoker, J. 2002. Honour your contribution, Risk 5: 90-94.

Kurth, A.; Tasche, D. 2003. Credit risk contributions to Value-at-Risk and expected shortfall, Risk 16: 84-88.

Li, B.; Liu, B. 2010. Return predictability and state variables in consumption-based CAPMs: international perspectives, Journal of Finance and Economics 51: 133-161.

Ludvigson, S. C.; Ng, S. 2007. The empirical risk-return relation: a factor analysis approach, Journal of Financial Economics 83: 171-222. http://dx.doi.org/10.1016/j.jfineco.2005.12.002

Markowitz, H. M. 1952. Portfolio selection, Journal of Finance 7: 77-91.

Martens, M.; Poon, S. 2001. Returns synchronization and daily correlation dynamics between international stock markets, Journal of Banking and Finance 25: 1805-1827.

http://dx.doi.org/10.1016/S0378-4266(00)00159-X

Michelfelder, R. A. 2005. Volatility of stock returns: emerging and mature markets, Managerial Finance 31: 66-86. http://dx.doi.org/10.1108/03074350510769505

Ou, S.; Yi, D. 2010. Constructing risk measurement models by quantile regression method, Working Paper. 2010 Third International Conference on Business Intelligence and Financial Engineering.

Petkova, R. 2006. Do the Fama-French factors proxy for innovations in predictive variables?, Journal of Finance 61: 581-612. http://dx.doi.org/10.1111/j.1540-6261.2006.00849.x

Praschnik, J.; Hayt, G.; Principato, A. 2001. Calculating the contribution, Risk (October): 25-27.

Rubin, R; Greenspan, A.; Levitt, A.; Born, B. 1999. Hedge funds, leverage, and the lessons of long-term capital management, Report of The President's Working Group on Financial Markets.

Schaumburg, J. 2010. Predicting extreme VaR: nonparametric quantile regression with refinements from extreme value theory, Working Paper. Humboldt-Universität zu Berlin.

Scheicher, M. 2001. The Co-movements of stock markets in Hungary, Poland and the Czech Republic, International Journal of Finance and Economics 6: 27-39.

http://dx.doi.org/10.1002/ijfe.141

Sheu, H. J.; Cheng, C. L. 2011. A study of China's and U.S. volatility spillover effects on Hong Kong and Taiwan, Africa Journal of Business and Management 5(13): 5222-5240.

Suhobokov, A. 2007. Application of Monte Carlo simulation methods in risk management, Journal of Business Economics and Management 8: 165-168.

Tarashev, N.; Borio, C.; Tsatsaronis, K. 2010. Attributing systemic risk to individual institutions, Working Paper. Bank for International Settlements. 
Vassalou, M. 2003. News related to future GDP growth as a risk factor in equity returns, Journal of Financial Economics 68: 47-73. http://dx.doi.org/10.1016/S0304-405X(02)00248-9

Wong, A.; Fong, T. 2010. Analysing interconnectivity among economies, Working Paper. Hong Kong Monetary Authority.

Worthington, A.; Higgs, H. 2004. Transmission of equity returns and volatility in Asian developed and emerging markets: a multivariate GARCH analysis, International Journal of Finance and Economics 9: 71-80. http://dx.doi.org/10.1002/ijfe.222

Her-Jiun SHEU received his PhD from Stern Business School, New York University in 1989. He is currently a professor of finance in the Department of Banking and Finance at National Chi Nan University, Taiwan. His research and teaching interests lie in financial management, derivatives, mathematical programming as well as management science.

Chien-Ling CHENG is currently studying in the PhD program of Institute of Business and Management, Management of National Chiao-Tung University, Taiwan. His primary research interests include financial theory, accounting, banking, and risk management. He is also the Senior Vice President of The Shanghai Commercial and Savings Bank Ltd, Taiwan. 